\title{
EXPLORING THE ROLE OF SELF-EFFICACY IN THE IMPLEMENTATION OF SELF-ASSESSMENT FOR ENGLISH WRITING
}

\author{
Paramartha, A.A.G.Y. \\ English Education Department, \\ Ganesha University of Education, Indonesia \\ E-mail: yudha.paramartha@undiksha.ac.id
}

\begin{abstract}
Many researchers have pointed out that the use of self-assessment gives positive effect on students' writing performance. However, some other factors, such as students' self-efficacy which may also play a role for students' success in writing is still rarely studied. Both self-assessment and self-efficacy share linear effect on students' writing performance. Thus, observing students with high and low selfefficacy while they are using self-assessment in writing is considerably noteworthy to study. This research is interested in investigating the role of high and low selfefficacy in the implementation of self-assessment for English writing. The design of the research was Pre-experimental Design of One-Shot Case Study with the sample of 42 students. The data were collected by using self-efficacy questionnaire and writing competency scoring rubric. The data were analyzed by using t-test. The result shows that there is a significant difference between students with high and low self-efficacy on the implementation of self-assessment for English writing.
\end{abstract}

Keywords:English writing, self-assessment, self-efficacy

\section{INTRODUCTION}

Writing is often considered as the most difficult language skill to be learnt because of its complexity. Not only in the matter of linguistic ability, writing also involves various cognitive and creativity process. In cognitive process of writing, writing is viewed as a process of transaction between writer schemes which consist of variety of information. In creative process of writing, the writing process is characterized by the insight of unique new ideas which is logically and uniquely arranged in writing.

Other aspects to become challenging for students are also found related to the structural rules of writing. It involves the dimension of content and development, vocabulary and style, grammar and structure, and the generic structures. Related to content and development, students find it difficult to develop their ideas and to organize them to make it coherent. Students often get confused to develop their paragraphs like which supporting details are appropriate to be put to support the controlling idea. The decision whether they have put sufficient ideas on the text is also another problem faced by them.

To overcome their difficulties in writing, self-assessment is considered effective to be implemented. Many

Jurnal Pendidikan Indonesia |56 
researchers have proven that the use of self-assessment can help students to develop their writing (Johnson \& Gelfand, 2013; Khodadady \& Khodabakhshzade, 2012; Kulkarni et al., 2015). Self-assessment can promote learning in writing because it gives learners training in evaluation which is important for autonomous learning. Students need to be able to make reliable and valid judgments. When learner are asked questions about what and how they have written, it generates evaluative attitudes of the students and improve goal-orientation because they can control their writing (Black, Harrison, Lee, Marshal, \& Wiliam, 2004).

Self-assessment can be conducted not only for assessment strategy; it also can be used for teaching strategy. Self-assessment as teaching strategy can focus students and emphasize assessment as a process of metacognition (Earl \& Katz, 2006). It comes from the idea that learning is not just a matter of transferring ideas from someone who is knowledgeable to someone who is not, but it is an active cognitive process that occurs when they develop their idea. Thus, selfassessment as a teaching and learning strategy can bring benefits which enables students to be aware of monitoring what they learn, and can make adjustment, adaptation, improvement, and change in their writing (Earl \& Katz, 2006). Feedbacks in writing that the students get by doing self-assessment will be meaningful if students have beliefs that they are able to assess the writing. If they do not have any kind of belief, the quality of their assessment can be considered questionable. Students' belief in their ability in writing affects the students writing competency.

Consideringthe students' belief in their ability in writing can influence their success in writing, it is important to consider students' self-efficacy which affects students' capability to do evaluation on their writing and students' writing competency. Self-efficacy is a person's belief in his or her ability to succeed in a particular situation (Bandura, 1995). It is a person's belief in their own competence. One who has a high level of self-efficacy is capable of performing a task to achieve certain goal. Related to writing, self-efficacy is the students' belief about their ability to be successful in doing the task of writing. Students tend to take a writing task if they believe they can succeed. They generally avoid writing task if their self-efficacy is low, but will engage in it when their self-efficacy is high. Related to their actual ability, students with high self-efficacy will be successful in writing, and those with low self-efficacy tend to fail in writing.

Self-assessment strategy and self-efficacy play a positive and linear role toward the success of students writing. However, the study about the role of self-efficacy together with the use of self-assessment strategy to accommodate students' writing performance is still very limited to find. That being said, it is logical to consider students' self-efficacy when they use self-assessment to help them in writing. Self-assessment strategy will give positive feedbacks for students writing, while self-efficacy of students also take a significant role for their success in writing. Thus, observing students with high and low self-efficacy while they are 
using self-assessment in writing is considerably noteworthy to study. This research is interested in investigating the role of high and low self-efficacy in the implementation of self-assessment for English writing.

The problem encountered for this research is whether there is a significant difference between students with high and low self-efficacy on the implementation of self-assessment for English writing. Thus, the hypothesis used is there is no significant difference between students with high and low selfefficacy on the implementation of selfassessment for English writing.

The result of this study is expected to strengthen the theory of self-efficacy and self-assessment in writing and give richer knowledge about difference between students with high and low self-efficacy on the implementation of self-assessment for English writing.

The theoretical reviews needed to construct the logic for this research are divided into three: the nature of writing, self-assessment in writing, and self-efficacy in learning.

\section{a. The Nature of Writing}

Writing is the art of maintaining ideas and feelings using a visual textual representation. It is maintained using a language that contains words and idioms that is unique to every people who are writing (Rijlaarsdam, Bergh, \& Couzijn, 2004). Writing is also considered as a form of indirect communication. As a form of indirect communication, writing needs to be developed thoughtfully to make it easy to be understood by readers. To do so, the writer needs to know his target readers' interest and the language choices which are appropriate for the readers.

To be a good writer is not an easy job. Everyone has difficulties in writing, how to find the idea, how to organize the idea, how to construct meaning, what words choices and grammars to be used are the basic problems in writing. But with a strong motivation and efforts, they can produce a good product of writing. It is certain that writing is a skill anyone can learn to make (Rijlaarsdam et al., 2004).

Writing is formal and includes a complex process that allows to the revision of irrelevant ideas (Hyland, 2003). For formal written English, the requirement is higher than spoken language in terms of grammar, vocabulary, and any other technical requirements, such as spelling, punctuation, capitalization, etc. Since writing takes a conscious effort that should link various aspects and skills to form a good piece of writing, it is difficult for the learners to deal with all those requirements, which undertake a process forward and backward, editing, revising, drafting, and so forth. Those characteristics which differentiate between speaking and writing can be used as a guidance to plan specific treatment toward written texts in educational field.

When people are writing they need to be able to arrange statements, argumentation or comments into wellorganized paragraph or text. It is needed to use understandable words to convey the meaning or the ideas. When the writer provides the reader a written form of ideas, it cannot be taken back since it is a permanent way to deliver an idea. 
There will be no chance to add clarifications or further explanations when the readers comment on it. Therefore, the writer needs to be careful in the writing process (Hyland, 2003).

Students must have specific purposes of writing in order to take control on their own writing. Students need to specify it in order to determine the nature of their writing. They need clear specification of the purpose in order to plan and compose a writing that meets the need of the given task (O'Malley \& Pierce, 1996). Knowing a clear specification of what the students will write will help them to choose and use the appropriate language, styles, and structures of the their composition.

The students' writing ability may vary depending on the purpose of writing. For example, a student who writes an excellent narrative writing may not be able to write a good persuasive writing. Furthermore, even in the same purpose, students' ability may vary. It depends on the topic which the students find it matches with their prior knowledge. When they are given a topic which they consider matching with their prior knowledge, they will find it easier to develop their writing.

Writing skills help the learners to gain independence, comprehensibility, fluency and creativity in writing (Rijlaarsdam et al., 2004). If learners have mastered these skills, they will be able to write, so that, not only they can read what they have written, but other speakers of that language can read and understand it. It means that writing skills are specific abilities which help writers put their thoughts into words in a meaningful form and to interact with the message.
Writing is unique for every individual that may use different methods to express him or herself. According to Langan (2013) there are many stages in writing and these stages may overlap to each other. Thus, Langan develop four stages of writing process. They are prewriting, drafting, revising, and editing.

In prewriting, students spend times to think and plan what they want to write. It often involves how to express their thought to writing, motivation in writing, and audience awareness. Further, the writer has to think about what he/she is trying to communicate, why it is worthwhile to be written, and who the audiences for this communication are.

Drafting is the preliminary stage of writing in which the author begins to develop a more cohesive product. A draft also describes the product the writer creates in the initial stages of the writing process (Langan, 2013). In the drafting stage, the author should develop a more cohesive text, organize thoughts, explain examples/ideas, discover a central argument/point, and elaborate ideas. Drafting is a necessary stage for the writer in the writing process. Having created a draft, the writer is then able to move onto the revision.

Revision is the stage in the writing process where the writer reviews what has been written in the draft (Langan, 2013). This process allows writers to take into account new ideas and thoughts and to have the opportunity to incorporate it into their writing.

Editing can be done through proofreading. The proofreading is 
effectively done to know which parts of the writing which need to be edited. The editing can be done while or after drafting. The writer can make all the necessary changes within the most recent draft (Langan, 2013).

\section{b. Self-assessment in Writing}

In writing instruction, selfassessment has a very significant role. There are several stages in the writing process which need much consideration along the process (Langan, 2013; O'Malley \& Pierce, 1996). Thus, selfassessment can be useful to students to monitor the progress of their own writing (Hyland, 2003). By implementing selfassessment when writing, students will become proactive in finding their strength and weaknesses. Knowing their own weaknesses, they can make plans to improve the quality of their writing along the process. Moreover, the students can work together with their peers (by administering peerassessment) and teacher and get some suggestion and recommendation to improve the quality of their composition.

Self-assessment is applicable not only to assess the writing they have made. It is applicable from the beginning, along the process, and also until the last stage of the writing. In the beginning of this process, students can use self-assessment as a basic guidance to develop their writing. Thus, they will have a standing point and will not be lost during the process. Along the process of writing, self-assessment is effectively applicable. It can be used to assess and develop their own writing. The use of self-assessment will be effectively and maximally used during the process of writing. Meanwhile, self- assessment can be used to recheck and make a confirmation about the writing they have made and decide whether it has been a good writing.

Self-assessment in writing can be implemented by several ways. The most commonly used tool is by using students' checklist (O'Malley \& Pierce, 1996). Checklist is useful in evaluating the writing skill that can be divided into a series of specific action. Selfassessment checklist covers the content, development, purpose, organization, grammar, vocabulary, style, and mechanics of writing. It is used to monitor students' performance in their own writing. It is also can be completed by administering an anecdotal record to point out some suggestion, correction, and recommendation from their teacher or their friends.

\section{c. Self-efficacy in Learning}

Perceived Academic self-efficacy

is defined as personal judgments of one's capabilities to organize and execute an action to accomplish educational performances (Bandura, 1995). Perceived academic self-efficacy can be measured by its level, generality, and strength. Self-efficacy level refers to variations across different levels of tasks, such as increasingly complex grammatical problems. Generality is related to the transfer of self-efficacy beliefs across activities, such as specific situation can be generalized to other situation and different subject matters. Strength is measured by degrees of belief that one can perform given tasks.

Self-efficacy involves judgments of capabilities to perform activities rather than personal qualities. Students judge 
their capabilities to fulfill given task, not how they feel about themselves in general. Efficacy beliefs are multidimensional rather than a single character. Consequently, efficacy beliefs are linked to different domains of functioning. Thus, efficacy belief of science will be different with English, for example. It is also context-dependent. Meaning that self-efficacy can appear differently when the context of learning is different. For example, students may express a lower sense of efficacy to learn in English than in mathematics. Students rate their belief that they can solve, for example, grammatical problems of varying difficulty, not how well they are compared to other students. Self-efficacy is measured before students perform the relevant activities (Zimmerman, 2000).

When tasks are given by the teacher, self-efficacious students will solve them quicker than those who doubt their capabilities. Therefore, the motivation effects of efficacy beliefs are best tested on difficultproblems. On these kind oftasks, students with high self-efficacy tend to be more persistent than those with low selfefficacy.Students with a high sense of efficacy will undertake difficult and challenging tasks readily, meanwhile those who are doubtful of their capabilities will avoid difficult tasks. Providing feedback to the students increase not only their perceptions of self-efficacy but also their choice of this task.

In conclusion, self-efficacy in education is called as perceived academic self-efficacy which is defined as one's belief of their competency in a specific educational performance and can be measured through its level, generality, and strength. It is contextdependent which means self-efficacy of someone can appear differently when the context of learning is different. Thus, for example, a person's level of selfefficacy in writing may appear differently with his level of self-efficacy in speaking. There has already some researches concerning about selfassessment and self-efficacy in writing. The followings are four of the researches done previously.

The effectiveness of using selfassessment on writing performance was proven by (Johnson \& Gelfand, 2013). He did a research to investigate the improvement of students' writing by administering self-assessment with the use of a co-created rubric. The result of the result showed that by the end of the research, the number of poor writing students decreased significantly. Moreover, many students reported to have more positive view about how they saw themselves as writers and more positive attitude toward writing.

The above research shared the similar finding to a research done by Khodadady \& Khodabakhshzade (2012). Their findings showed that selfassessment, as a part of portfolio assessment, could give a significant effect, not only for students' writing ability, but also for the autonomy in developing their writing. The regular use of self-assessment enabled the students to work on their writing autonomously. Even at the beginning of using it they found some difficulties, but over time, they were able to assess their own work and successful in developing their writing piece by their own. 
The effect of self-efficacy can be found in a research by Prat-Sala \& Redford (2012). It was about the relationship between self-efficacy in reading and self-efficacy in writing on students' performance in essay writing showed that self-efficacy in writing were significantly related to essay writing performance in both first and second year psychology undergraduate students. An interesting finding from this research was that the second year students could perform slightly better than the first year students. It was argued that since the second year students would have had more experience in writing essay, thus they would have got more feedbacks as their self-efficacy and their confidence in writing were better than the first year. Knowing that, it was no surprising to see their performance was better that those of the first year students.

Positive effect of self-efficacy on writing performance was also investigated by Tanyer (2015). His research about the role of writing and reading self-efficacy in pre-service EFL teachers' writing performance suggested that self-efficacy beliefs were predictive to foreign language essay writing performance. His research also showed that self-efficacy is specific to a particular writing task. For example, writing self-efficacy in narrative genre may not be generalized to self-efficacy in descriptive genre. To see the parallelism of self-efficacy among genres, further study is needed.

Based on the above researches, it has become a fact that both selfassessment and self-efficacy share positive and linear effect on students' writing performance. Thus, to investigate about the effect of both is notably essential to study. For this research, it is predicted that the use of selfassessment strategy will be more meaningful if the students have high self-efficacy in writing.

\section{METHOD}

This study is interested in investigating the role of self-efficacy in the implementation of self-assessment for English writing. The sample for this research was 42 students of SMA Negeri 4 Singaraja in an intact class. From this class, the students were grouped based on their self-efficacy score; a group of 21 students with low self-efficacy and another group of 21 students with high self-efficacy. Both groups were treated by using selfassessment strategy in writing.

The design used for this study was Pre-experimental Design of OneShot Case Study to investigate the role of self-efficacy in the implementation of self-assessment for English writing. This research primarily focused on comparing the writing competency of students with high self-efficacy and those with low self-efficacy as a way to see the role of self-efficacy in the implementation of self-assessment for English writing.

There were three variables used for this study: independent, moderator, and dependent variable. Independent variables in this research was selfassessment strategy in writing. In this research, the moderator variable was the level of self-efficacy; high selfefficacy and low self-efficacy. The dependent variable in this study was the writing competency. 
The data were collected by using a questionnaire of self-efficacy in writing and a scoring rubric of writing competency. The data were analyzed by using descriptive statistics and t-test to compare the writing competency of students with high self-efficacy and those with low self-efficacy.

\section{FINDINGS AND DISCUSSION}

This research aimed at investigating the role of self-efficacy in the implementation of self-assessment for English writing. The result can be seen by comparing the writing competency of students with high selfefficacy and those with low self-efficacy. The following table represents the description of the data of both groups.

Table 1. The Description of writing score of students with high and low self-efficacy treated by using self-assessment strategy

\begin{tabular}{ccc}
\hline Statistic & High Selft-Efficacy & Low Selft-Efficacy \\
\hline Mean & 83.14 & 75.05 \\
Range & 30.00 & 24.00 \\
Variance & 63.82 & 55.85 \\
Standard Deviation & 7.99 & 7.47 \\
Maximum Score & 96.00 & 86.00 \\
Minimum Score & 66.00 & 62.00
\end{tabular}

The table 1 above shows the data description of both groups. The group of students with high self-efficacy treated by using self-assessment strategy has the mean score of 83.14 , range of 30.00 , variance of 63.82 , standard deviation of 7.99 , maximum score of 96.00 , and minimum score of
66.00. On the other hand, the group of students with high self-efficacy treated by using self-assessment strategy has lower score for the mean score (75.05), maximum score (86.00) and minimum score (62.00). The following plot shows the mean score comparison between high and low self-efficacy students.

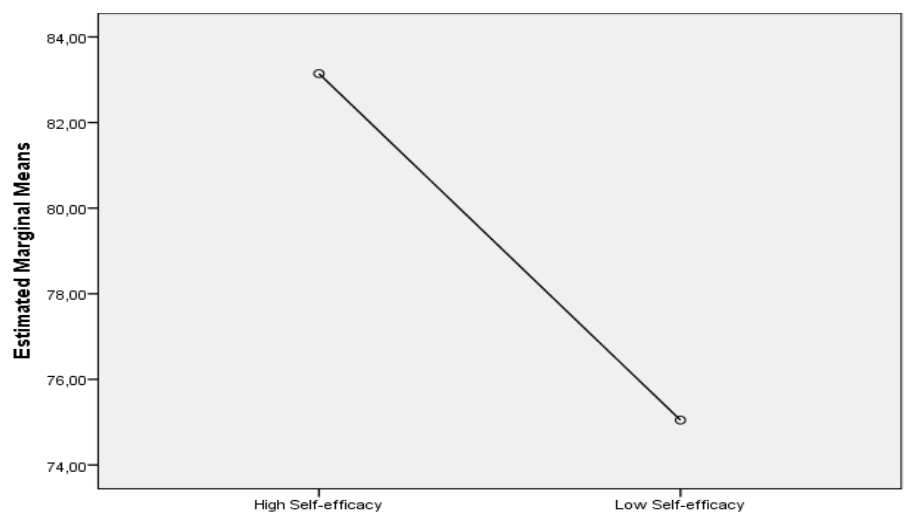

Picture 1. Mean score comparison between group of students with high and low selfefficacy 
Viewed from the mean score shown in the picture 1, the group of students with high self-efficacy treated by using self-assessment strategy achieved better that the group of students with low self-efficacy treated by using self-assessment strategy (83.14 compared to 75.05). Based on this finding, it is known that, since both groups are treated by using selfassessment strategy, high self-efficacy students can maximize the potency given by the implementation of selfassessment strategy. The positive effect of having high self-efficacy can also be observed based on the minimum and maximum scores from the two groups. The maximum score from the group of students with high self-efficacy is better that the other group by 10 points. The same trend can also be seen from the minimum score in which the difference between the two groups is 4 points for the students with high self-efficacy.

Besides observing the description of the data, testing the hypothesis also needs to be done. The hypothesis for this research is there is no significant difference between students with high and low self-efficacy on the implementation of selfassessment for English writing. A t-test was administered to the normally distributed and variance-homogenous data. The result of hypothesis testing can be seen from the following table.

Table 2. The result of hypothesis testing

\begin{tabular}{cc}
\hline Statistic & Value \\
\hline $\mathrm{t}$ & 3.391 \\
$\mathrm{df}$ & 40 \\
Significance value & 0.002 \\
Mean difference & 8.095
\end{tabular}

The hypothesis testing shows that the value of $t$ is 3.391 with the significance value of 0.002 or $p$ is under $0.050(p<0.05)$. It means that the null hypothesis is rejected. Thus, it is concluded that there is a significant difference between students with high and low self-efficacy on the implementation of self-assessment for English writing. This difference shows that the use of self-assessment strategy can affect significantly to student's writing competency when they have high-self efficacy.

Based on the data analysis, it is clear that students with high self-efficacy achieved better that those with low selfefficacy. Students with high self-efficacy will undertake difficult and challenging tasks readily. Students need guidance in form of feedbacks to develop their writing since they are not familiar to do it. By using feedbacks, they are able to know their weaknesses and then can improve it. Students with high selfefficacy tend to be active in finding out weaknesses on the task, thus they need feedbacks to help them finding the weaknesses and developing their writing. Providing feedbacks is the core of self-assessment strategy. That is why self-assessment strategy is suitable for students with high self-efficacy.

As a strategy which emphasizes on the process of writing, selfassessment strategy can give students 
constant feedbacks to do the evaluation and reflection when they develop their writing. Furthermore, the use of selfassessment strategy will be meaningful if students have beliefs that they are able to assess the writing. If they do not have any kind of belief, the quality of their assessment can be considered questionable. Thus, it can be concluded that treating students with high selfefficacy using self-assessment strategy will bring a positive and significant value for their success in writing.

The observation done toward the students with high self-efficacy treated using self-assessment strategy also shows how they could achieve better than those with low self-efficacy. On the first time the students were asked to make their writing, the instructor did not give them any self-assessment checklist to assist them. Nevertheless, they enthusiastically engaged on the task since they had belief in their selves that they could do it (based on the result of their self-efficacy questionnaire responses). When they had made the first draft of the writing, the instructor asked them whether they faced some problems. Some of the high self-efficacy students responded by telling him that they did not find any significant problems. The high belief of accomplishing the task might lead them to feel that they had done the task successfully.

The instructor started giving them self-assessment checklist and explained them how to use it. It was observed that the students started to realize that they made some mistakes after using self-assessment checklist. For example, when the students were in the process of developing narrative essay, a student asked him about a statement on the checklist of "using appropriate tenses". She knew that she had to use simple past tense, however, she was still doubtful that she had used it appropriately. She rechecked her writing and also asked the instructor about something that she was not so sure about. It proves that the use of selfassessment checklist could be used to remind her to recheck and make sure that she had made good writing. Another high self-efficacy student also asked the statement of "I use synonym and antonym to avoid repetition". He actually did not understand about the statement, but he tried to ensure that he had fulfilled the expectation of the statement. After the instructor explained it to him and the class, he realized that he made some word repetitions like "the thief" over and over again.

Self-assessment strategy can also help low self-efficacy students in developing writing since it provides guidance for the students to assess their own writing. However, it was observed that their nature of having low selfefficacy influenced more on their performance in writing. On the other words, it was hard to engage them in writing because they did not have any belief that they would become successful in writing. It made them did not have any goal, motivation, or desire to write. The observation on the second meeting (the day when the selfassessment checklist was firstly distributed) shows the reluctance of them. When the students were asked to check on the statements when their writing had met the criteria, some of them checked on the statement without evaluating their writing instead. On the 
other hand, some of them did not check anything on the checklist. When the instructor asked them, they just reluctantly said that they did not understand what to do or did not know whether they made some mistakes.

The above discussion shows that there is a relation among the nature of writing competency, self-assessment strategy, and self-efficacy in writing. Writing is a cognitive and creative process which requires the ability and self-belief to create ideas and arrange the ideas to become interesting, meaningful, and creative. A creative writer always try to look back to evaluate their writing whether or not he has made a good writing. He will do it over and over again until he becomes satisfied that his writing has been a good one.

The need of evaluation in the process of writing can be covered by self-assessment strategy since its core is self-evaluation in the process of writing. Through evaluation, a writer can see the strengths and weaknesses of his writing. It means that, by doing selfassessment, he can get meaningful feedbacks. These feedbacks will enable them to produce a good, satisfying writing.

Meanwhile, the nature of selfefficacy is someone's belief in doing particular task, in this case doing writing. Students with high self-efficacy in writing believe that they are able to follow the complex process of writing and as the result, they will be successful. By having high self-belief, they will have motivation and goal. However, if they do not get appropriate feedbacks, it may lead them to be overconfident and underestimate the process of writing. Furthermore, the consequence is they will be failed instead of successful in writing.

The natures of those three aspects; writing competency, selfassessment strategy, and self-efficacy bind together and can explain the result of this research. The nature of creative and cognitive process of writing competency can be well maintained by maximizing the evaluative nature of selfassessment strategy. The evaluative nature of self-assessment to get good writing is relevant for them who have high self-efficacy. Doing selfassessment in writing will positively contribute to the success in writing if the students believe that they are able to do it. On the other hand, students with high self-efficacy need evaluative feedbacks to control and maximize their belief in writing. In conclusion, students will be able to reach their best result in writing if they have high self-efficacy and learning writing using self-assessment strategy.

\section{CONCLUSSIONS}

Based on the finding and discussion above, it is concluded that students with high self-efficacy treated by using self-assessment strategy achieve significantly better than those with low self-efficacy. From this result, it can be inferred that the use of selfassessment strategy will be more meaningful if the students have high self-efficacy in writing.

Self-assessment strategy shares similar and positive nature with high selfefficacy students. Students with high self-efficacy tend to be more active in finding out weaknesses on their writing. The use of feedbacks provided by selfassessment strategy can activate their belief higher to solve the problems in 
writing. That is why self-assessment strategy is suitable for students with high self-efficacy. As a strategy which emphasize on the process of writing, self-assessment strategy can give students constant feedbacks to do the evaluation and reflection as they develop their writing. Furthermore, the use of self-assessment can maximally effective if students have high belief that they are able to assess the writing.

The observation on low selfefficacy students shows that although the use of self-assessment gave an effect to their writing, the nature of having low self-efficacy influenced more on their writing performance. It was hard to engage them in writing because they did not have any belief that they would become successful in writing.Thus, it was not a surprise that they perform considerably lower than those with high self-efficacy.

Considering self-efficacy plays significant role on students' writing performance while they are using selfassessment, it is recommended that the teacher should consider their students' self-efficacy in advance. If the students have already had notably high selfefficacy, the self-assessment on writing can surely be used by them and it will give significant effect on their writing performance. On the other hand, if the students still have low self-efficacy, it is recommended that the teacher should make some efforts to increase their belief in completing the task in writing before giving the self-assessment to accommodate their writing performance.

\section{REFERENCES}

Bandura, A. (1995). Self-efficacy in changing societies. Cambridge university press.

Black, P., Harrison, C., Lee, C., Marshal, B., \& Wiliam, D. (2004). Assessment for Writing: Putting It into Practice. England: Mc Graw Hill Education.

Earl, L. M., \& Katz, M. S. (2006). Rethinking classroom assessment with purpose in mind: Assessment for learning, assessment as learning, assessment of learning. Manitoba Education, Citizenship \& Youth.

Hyland, K. (2003). Second language writing. Ernst Klett Sprachen.

Johnson, C. S., \& Gelfand, S. (2013). Self-assessment and writing quality. Academic Research International, 4(4), 571.

Khodadady, E., \& Khodabakhshzade, H. (2012). The effect of portfolio and self assessment on writing ability and autonomy. Journal of Language Teaching and Research, 3.

Kulkarni, C., Wei, K. P., Le, H., Chia, D., Papadopoulos, K., Cheng, J., ... Klemmer, S. R. (2015). Peer and self assessment in massive online classes. In Design thinking research (pp. 131-168). Springer.

Langan, J. (2013). College writing skills with readings. Tata McGraw-Hill Education.

O'Malley, J. M., \& Pierce, L. V. (1996). Authentic assessment for English language learners: Practical approaches for teachers. AddisonWesley Publishing Company New York. 
Prat-Sala, M., \& Redford, P. (2012). Writing essays: Does self-efficacy matter? The relationship between self-efficacy in reading and in writing and undergraduate students' performance in essay writing. Educational Psychology, 32(1), 9-20.

Rijlaarsdam, G., Bergh, H., \& Couzijn, M. (2004). Effective learning and teaching of writing: $A$ handbook of writing in education (Vol. 14). Springer Science \& Business Media.
Tanyer, S. (2015). The role of writing and reading self-efficacy in firstyear preservice EFL teachers' writing performance. ProcediaSocial and Behavioral Sciences, 199, 38-43.

Zimmerman, B. J. (2000). Self-efficacy: An essential motive to learn. Contemporary Educational Psychology, 25(1), 82-91. 